\title{
El documentalista audiovisual
}

\section{Por Montserrat Bailac y Montserrat Català}

ESTA BREVE NOTA presenta el análisis de una especialidad que tradicionalmente ha estado considerada como una rama de la Biblioteconomía-Documentación.

Se entiende como documentalista el profesional que trabaja en un centro de documentación. El término "documentalista audiovisual" nace vinculado al mundo de la imagen en movimiento, el cine y la televisión. Desde el punto de vista terminológico, la misma palabra se utiliza para designar profesionales que llevan a cabo diferentes tareas. En el mundo anglosajón, cada una de estas vertientes tiene una denominación propia: archivist, video librarian y researcher.
Hoy en día, y dado el grado de divulgación y popularidad del material audiovisual, éste se puede encontrar en centros muy diversos como productoras de vídeo, ayuntamientos, empresas, bibliotecas, archivos, etc., que dan un tratamiento documental similar a su material, aunque adaptado a las propias necesidades. Este hecho provoca la necesidad de formación específica de los profesionales que lo deban tratar.

En nuestro entorno, la irrupción del material audiovisual en todo tipo de centros, ya sean específicos (televisiones...) como generales (bibliotecas, archivos...) ha provocado la constatación de ciertas lagunas en la formación que se puede adquirir actualmente en las universidades en este ámbito. Las facultades que imparten los estudios de biblioteconomía y documentación siguen ofreciendo las asignaturas más clásicas y generalmente vinculadas al mundo de la biblioteca tradicional de libros, y han modernizado sus diseños curriculares sólo con temas de informática, internet y nuevas tecnologías, pero sin profundizar en los relacionados con la imagen y el sonido.

Para superar estas deficiencias, las empresas y los profesionales del sector han optado por ofrecer / buscar formación específica continuada mediante cursos sobre materias técnicas del mundo de la imagen, impartidos por especialistas en ca- 

da una de éstas, por adaptar la bibliografía publicada en otros países sobre documentación audiovisual, y por mantener contactos con centros similares del extranjero, organizando visitas de intercambio.

\section{Tres sub-especialidades}

La diversidad de centros en los que podemos encontrar el material audiovisual ha provocado diferentes funciones del documentalista. Por una parte los documentalistas o archiveros audiovisuales (archivists) ligados normalmente a una empresa de producción audiovisual, entre cuyas tareas principales podemos encontrar el análisis del material: la descripción de la imagen misma o del programa, reportaje, etc., en su conjunto para su posterior recuperación al servicio de la empresa para la que trabajan.

Por otro lado, encontramos al bibliotecario o documentalista ( $v i$ deo librarians) que gestiona los fondos audiovisuales de una biblioteca con múltiples soportes no necesariamente vinculada de forma exclusiva al mundo de la imagen-.

El especialista en recuperación (researcher) sería la tercera acepción de la profesión de documentalista audiovisual. Correspondería al profesional que busca documentación en cualquier soporte documental para un periodista, realiza-

El profesional de la información está abierto a todos los bibliotecarios, documentalistas y otros profesionales de la información, así como a las empresas y organizaciones del sector para que puedan exponer sus noticias, productos, servicios, experiencias y opiniones.

Dirigir todas las colaboraciones para publicar a:

El profesional de la información

Apartado 32.280

08080 Barcelona

Fax: +34-932 081971

epi@sarenet.es nado, conocimiento de los archivos del país y extranjeros, archivos en la red, y práctica en idiomas. Aparte del conocimiento del tipo de fondo de los archivos, es también necesaria una buena organización del tiempo, planificación de las consultas y una gran capacidad de adaptación para el trabajo en grupo y la integración en los diferentes equipos de producción con quien corresponda trabajar.

\section{«Los estudios regla- dos han modernizado sus diseños curricu- lares con temas de informática, internet y nuevas tecnologías, pero no han profundi- zado en los relacio- nados con la imagen y el sonido»}

Las tres vertientes profesionales descritas pueden ser realizadas por un mismo profesional si se adquiere la debida formación. Se trata de una profesión pluridisciplinar como pocas, y por lo tanto, cuanto más amplia y variada sea la cultura del documentalista, más eficaz resultará en su trabajo. Pero, reiteramos, una buena base documental es imprescindible para obtener este objetivo.

La profesión de documentalista audiovisual tiene un gran futuro en un mundo en que la imagen se impone. Es necesario, por tanto, que los bibliotecarios-documentalistas adquieran la formación adecuada para afrontar los cambios que se avecinan. Las personas que consigan una mejor formación en este ámbito serán quienes ocupen las variantes profesionales que irán surgiendo con el tiempo.

\footnotetext{
Montserrat Bailac i Puigdellívol y Montserrat Català i Freixa

Documentalistas de Televisió de Catalunya (TVC) mbailac.l@tvcatalunya.com mcatala.r@tvcatalunya.com
} 